\title{
Influência da irrigação, da densidade de plantio e da adubação nitrogenada nas características morfogênicas, estruturais e de produção do capim-tanzânia
}

\author{
Marcela de Azevedo Magalhães ${ }^{1}$, Janaina Azevedo Martuscello ${ }^{2}$, Dilermando Miranda da \\ Fonseca $^{3}$, Ivanna Moraes de Oliveira ${ }^{4}$, Fabrício Paiva de Freitas ${ }^{5}$, Dawson José Guimarães \\ Faria $^{6}$, Rubens Alves de Oliveira ${ }^{3}$, José Ivo Ribeiro Júnior ${ }^{3}$
}

\author{
${ }^{1}$ Doutoranda Unesp/Jaboticabal. \\ 2 Departamento de Zootecnia/Universidade Federal de São João Del Rei. \\ ${ }^{3}$ Universidade Federal de Viçosa. \\ ${ }^{4}$ Doutoranda do Departamento de Zootecnia da UFV. \\ 5 Zootecnista autônomo. \\ ${ }^{6}$ Instituto Federal de Educação, Ciência e Tecnologia do Triângulo Mineiro, Campus Uberaba, MG.
}

RESUMO - O experimento foi conduzido com os objetivos de avaliar a altura do dossel com 95\% de interceptação luminosa e quantificar a influência da adubação nitrogenada e da densidade de plantas nas características morfogênicas e estruturais de

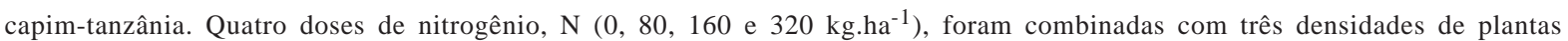
(9, 25 e 49 plantas. $\mathrm{m}^{-2}$ ), em um arranjo fatorial $4 \times 3$, em delineamento inteiramente casualizado com três repetições, para avaliação da produção de biomassa, e duas repetições, para avaliação das características morfogênicas e estruturais. O acúmulo de MS total durante o período experimental foi influenciado pela adubação nitrogenada e pela densidade de plantas. No período das águas, as maiores doses de nitrogênio diminuíram o intervalo de colheitas e, consequentemente, aumentaram o número de colheitas. A altura do dossel de capim-tanzânia com 95\% de IL foi positivamente influenciada pela densidade de plantas nos períodos das águas e de transição água-seca e seca. A altura do capim-tanzânia com 95\% de IL apresentou variações ao longo das avaliações, de modo que os valores foram maiores (próximos a $70 \mathrm{~cm}$ ) no período das águas, seguido pelos períodos de transição água-seca e seca.

Palavras-chave: densidade de semeadura, fertilização, Panicum maximum

\section{Morphogenesis and structural characteristics and production of guinea grass irrigated under different plants density and nitrogen doses}

\begin{abstract}
This experiment was carried out to evaluate canopy height of guinea grass with 95\% of photosynthetic active radiation interception and quantify the nitrogen fertilization influence and plants' density on the morphogenesis and structural characteristics of Tanzania grass. Four doses of $\mathrm{N}\left(0,80,160\right.$ e $\left.320 \mathrm{~kg}^{-h^{-1}}\right)$, were arranged with three plant densities (9, 25 and 49 plants. $\mathrm{m}^{-2}$ ), according to $4 \times 3$ completely randomized design, with three repetitions. Total dry matter (DM) accumulation throughout the experimental period was influenced by nitrogen fertilization and plants' density. In the rainy period, the higher nitrogen fertilization decreased the harvesting intervals, and consequently, increased the number of harvests. The rate of leaf appearance and the phyllochron were influenced only under nitrogen fertilization in the transition period of rainy and dry weather. Tanzania grass canopy height under $95 \%$ of light interception was positively influenced because of the plant densities in rainy period and transition period between rainy/drought and drought. Tanzania grass height under 95\% of light interception presented variations along the evaluations and the values were higher (near $70 \mathrm{~cm}$ ) in the rainy period, followed by transition period rain/drought and drought.
\end{abstract}

Key Words: density seed, fertilization, Panicum maximum

\section{Introdução}

Forrageiras da espécie Panicum maximum destacam-se pela alta produtividade e por serem altamente exigentes em manejo de forma geral. Várias cultivares dessa espécie foram lançadas no mercado nos últimos anos, porém poucas informações foram geradas acerca da otimização da utilização dessas forrageiras.

A produção animal em pastagens tropicais pode, em parte, ser otimizada com práticas de manejo que aumentem 
a eficiência de utilização da pastagem. De acordo com Hodgson (1985), variáveis arbitrárias, como taxa de lotação e duração do período de descanso, não podem ser consideradas determinantes primários da produção de forragem ou do desempenho animal, uma vez que seus efeitos são mediados pela estrutura do dossel.

De acordo com Da Silva (2004), em análise a partir de resultados de experimentos realizados para o manejo mais preciso do pastejo em capim-tanzânia, a condição de prépastejo de 95\% de interceptação luminosa (IL) está altamente relacionada à altura do dossel, que corresponde a $70 \mathrm{~cm}$, independentemente da época do ano e do estádio fenológico das plantas, indicando que a altura poderia ser utilizada como critério confiável para o monitoramento dos processos de rebrotação e pastejo.

O nitrogênio $(\mathrm{N})$, nutriente que afeta as características morfofisiológicas de plantas forrageiras, tem efeito direto no fluxo de tecidos (Martuscello et al., 2006; Martuscello et al., 2005; Alexandrino et al., 2004) e pode influenciar a altura em que o dossel intercepta 95\% da luz incidente, uma vez que acelera os processos de crescimento e senescência. Em maiores doses de nitrogênio, as plantas poderiam alcançar mais rapidamente a IL de $95 \%$ e a altura de $70 \mathrm{~cm}$ preconizada.

Assim, este trabalho foi realizado com o objetivo de avaliar as características morfogênicas e estruturais de capim-tanzânia sob doses de nitrogênio e densidades de plantas em condição pré-desfolha de $95 \%$ de interceptação da radiação fotossinteticamente ativa pelas plantas.

\section{Material e Métodos}

O experimento foi conduzido no período de janeiro a agosto de 2006. O tipo climático da região é Cwa, segundo a classificação de Köppen, com precipitação pluvial média anual em torno de $1.340 \mathrm{~mm}$, umidade relativa do ar de $80 \%$ e temperaturas médias máximas e mínimas de 27,3 e $14,9{ }^{\circ} \mathrm{C}$, respectivamente (Figuras 1 e 2).

Os tratamentos consistiram da combinação de quatro doses de $N\left(0,80,160\right.$ e $\left.320 \mathrm{~kg}^{\circ} \mathrm{ha}^{-1}\right)$ e de três densidades de plantas 9 , 25 e 49 plantas. $\mathrm{m}^{-2}$, correspondentes às taxas de semeadura de 1,12; 3,08 e 6,16 kg.ha ${ }^{-1}$ de sementes puras viáveis, segundo um arranjo fatorial $4 \times 3$, em delineamento inteiramente ao acaso, com três repetições para a avaliação de altura e produção de massa seca e 2 repetições para a avaliação das características morfogênicas e estruturais.

Para maior controle do número de plantas na área (plantas. $\mathrm{m}^{-2}$ ), optou-se pela semeadura da forrageira em bandejas com substrato agrícola comercial, em casa de vegetação, onde as plantas foram mantidas até atingirem

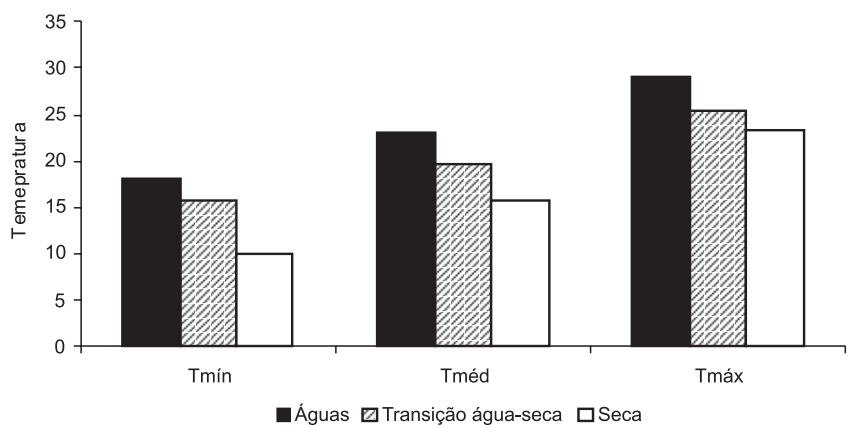

Figura 1 - Temperaturas mínima (Tmín), média (Tméd) e máxima (Tmáx), em ${ }^{\circ} \mathrm{C}$, nos períodos das águas e transição água-seca e de seca.

(Fonte: Departamento de Engenharia Agrícola/UFV).

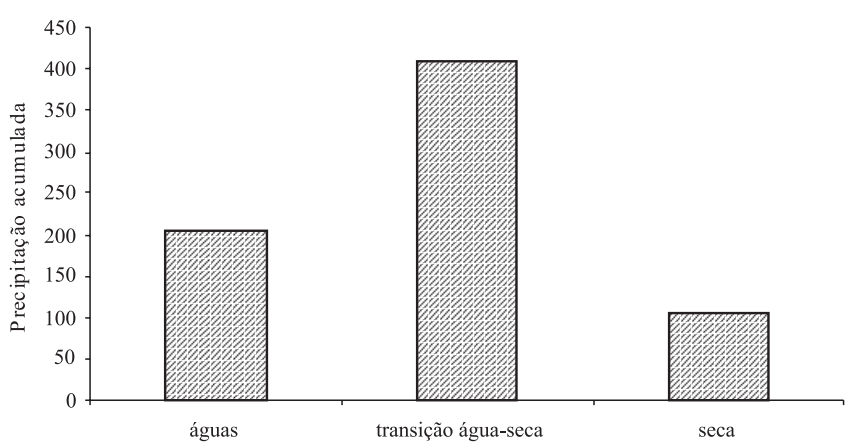

Figura 2 - Precipitação acumulada (mm) nos períodos das águas e de transição água-seca e de seca. (Fonte: Departamento de Engenharia Agrícola/UFV).

aproximadamente $15 \mathrm{~cm}$ de altura. Posteriormente, realizou-se a transplantação, de 9, 25 e 49 plantas.m ${ }^{-2}$, correspondentes às densidades de plantas em cada tratamento, em parcelas de $9 \mathrm{~m}^{2}$.

$\mathrm{Na}$ área experimental, antes da demarcação das parcelas, realizaram-se aração e gradagem do solo e posteriormente retiraram-se amostras de solo na camada de 0 a $20 \mathrm{~cm}$, para caracterização química e física, correção da acidez e aplicação de adubos necessários. A análise da amostra apresentou as seguintes características químicas: pH em água, 5,9 (relação 1:2,5); fósforo, 1,1; e potássio, $146 \mathrm{mg} \cdot \mathrm{dm}^{-3}$ (Extrator Mehlich-1); cálcio, 3,1; magnésio - 1,0; alumínio - 0,0 $\mathrm{cmol}_{c^{\prime}} \cdot \mathrm{dm}^{-3}$; e matéria orgânica-3,71 dag/kg. O solo da área experimental foi classificado como Latossolo Vermelho-Amarelo de textura argilosa. Efetuou-se a aplicação $110 \mathrm{~kg} \cdot h \mathrm{~h}^{-1} \mathrm{de} \mathrm{P}_{2} \mathrm{O}_{5}$ (superfosfato simples). As doses de nitrogênio (ureia) foram divididas em três aplicações: a primeira 30 dias após a transplantação (2/12/2005) e as outras duas após dois cortes sucessivos das plantas em cada parcela.

O experimento foi irrigado de acordo com a evapotranspiração da cultura (ETc) capim-tanzânia, estimada 
a partir da evapotranspiração de referência (ETo), obtida com o uso da equação de Penman-Monteth, FAO 56, e de coeficientes da cultura (Kc). Os valores de Kc utilizados na determinação da ETc diária foram obtidos por meio da equação Kc $=0,46+0,0321 *$ NDAC, sendo NDAC igual ao número de dias após a colheita, adaptada conforme descrito por Xavier et al. (2004) para a localidade de Pereira Barreto, São Paulo, aplicada conforme o estádio de desenvolvimento do capim-tanzânia. Os dados de temperatura máxima, mínima e média, precipitação pluvial e ETo foram obtidos em uma estação metereológica automática, instalada a $500 \mathrm{~m}$ da área experimental (Figuras 1 e 2). A partir desses cálculos, as parcelas experimentais foram irrigadas semanal e individualmente, por meio de um hidrômetro adaptado a um tubo de PVC perfurado conectado à rede de irrigação e deslocado sobre cada parcela a ser irrigada até completar o volume de água daquele turno de rega.

O controle de plantas invasoras nas parcelas foi feito manualmente, a intervalos de aproximadamente 30 dias.

Para avaliação das características morfogênicas, foram identificados dois perfilhos por parcela, em dois blocos (repetições), totalizando 24 unidades experimentais ou parcelas. Os perfilhos foram marcados após 20 dias da transplantação e as medidas feitas a cada dois dias durante os períodos das águas e transição água-seca e a cada sete dias durante o período seco. Foram medidos e registrados o comprimento da lâmina foliar e a altura da lígula da última folha expandida em relação ao nível do solo, além do registro de novas folhas surgidas em cada um dos perfilhos e em cada avaliação. As medidas de comprimento foram feitas com régua milimetrada durante todo o período experimental. A partir dos dados registrados no campo foram realizados os cálculos para determinação da taxa de aparecimento foliar (TApF); filocrono; taxa de alongamento foliar (TAlF); taxa de senescência foliar (TSF); número de folhas vivas (NFV) e taxa de alongamento do pseudocolmo (TAlPC).

Para avaliação dos padrões demográficos de perfilhos e de suas respectivas taxas de aparecimento e mortalidade, 32 dias após a transplantação, foram identificadas duas touceiras (unidade de amostragem) por parcela em dois blocos (repetições), totalizando 24 unidades experimentais ou parcelas. Todos os perfilhos existentes nas duas touceiras foram contados e marcados com arames revestidos de plástico colorido. A cada nova amostragem, realizada a intervalos de 21 dias para o período das águas e transição água-seca e a cada 30 dias para o período da seca, independentemente do tempo de rebrotação, novos perfilhos que surgiram nas mesmas touceiras, foram marcados com arames de cores diferentes de modo a se obter o número de perfilhos surgidos em cada marcação e o número de perfilhos mortos na geração anterior. Essas variáveis foram calculadas para cada touceira em cada avaliação, determinando-se as gerações. Os resultados por umidade experimental ou parcela foram provenientes da média de duas touceiras por unidade experimental. Assim, foi obtida a estimativa da população de perfilhos de todas as gerações (de acordo com as diferentes cores dos arames), o que permitiu o cálculo de suas respectivas taxas de aparecimento e mortalidade.

O monitoramento da interceptação luminosa (IL) e da altura do dossel foi realizado a intervalos de dois dias durante o período das águas e de transição água-seca e a cada sete dias durante o período seco. Além dos intervalos citados, quando os níveis de IL foram próximos a 95\%, a frequência de monitoramento foi aumentada, com avaliações realizadas diariamente. As medidas de altura do dossel de capim-tanzânia foram feitas todas as vezes que se procedeu à medição da IL, de modo a estabelecer uma relação entre altura e IL. Nas avaliações da IL, utilizou-se o aparelho analisador de dossel, denominado Sun Scan, com seis pontos de leituras por unidade experimental, três leituras na parte superior do dossel e três ao nível do solo. A altura do dossel foi determinada utilizando-se régua (1 $\mathrm{m}$ ) graduada em centímetros, com medições em seis pontos de cada unidade experimental.

Quando a interceptação da radiação fotossinteticamente ativa pelo dossel atingia 95\%, independentemente da altura das plantas de capim-tanzânia, efetuava-se a medida da altura e a colheita das plantas a partir de um corte a $20 \mathrm{~cm}$ em relação ao nível do solo em uma área de 0,60 × 1,3 m, na parte central da parcela. As amostras de forragem foram separadas em lâmina foliar, colmo + bainha e material morto. Esses componentes das amostras foram colocados em sacos de papel previamente identificados e levados a estufa de circulação forçada a $65{ }^{\circ} \mathrm{C}$ até peso constante.

Os dados relativos ao acúmulo de massa seca (MS) e à taxa de aparecimento e mortalidade de perfilhos foram analisados considerando todo o período experimental (janeiro a agosto), enquanto, para as demais variáveis, os resultados foram agrupados em período das águas (PA), de janeiro a fevereiro; período de transição água-seca (PT), de março a maio; e período seco (PS), de junho a agosto.

Os dados de MS acumulada durante o período de avaliação foram submetidos às análises de variância e regressão das médias de acordo com as doses de $\mathrm{N}$ e densidade de plantas, selecionando-se as equações pelo coeficiente de determinação $\left(\mathrm{R}^{2}\right)$ e pelo teste $\mathrm{t}$ a $5 \%$ de 
significância. Os dados de morfogênese foram agrupados por período e submetidos às mesmas análises estatísticas, porém para cada período separadamente.

\section{Resultados e Discussão}

No período de transição águas-seca, a taxa de alongamento foliar (TAlF) do capim-tanzânia foi influenciada positivamente pela adubação nitrogenada e negativamente pela densidade de plantas e, no período seco, apenas pela densidade de plantas (Tabela 1 ). No período das águas, a TAlF não foi influenciada $(\mathrm{P}>0,05)$ pela adubação nitrogenada nem pela densidade de plantas, sendo observada neste período de avaliação TAlF média de $7.75 \mathrm{~cm} /$ dia, valores semelhantes aos encontrados por Gomide \& Gomide (2000) e Cândido et al. (2005b) (6 a 8 cm/perfilho × dia) e superior ao encontrado por Bícego et al. (2003) (2.5 a $3.0 \mathrm{~cm} /$ folha $\times$ dia), em estudo com Panicum maximum cv. Tanzânia. Não foi observada interação entre os fatores para TAlF em nenhum dos períodos avaliados.

O incremento na TAlF com o aumento das doses de nitrogênio no período de transição água-seca pode ser atribuído ao maior número e tamanho de células produzidas em resposta à adubação nitrogenada, conforme constatado por Volenec \& Nelson (1984), em decorrência da deposição preferencial de nitrogênio na zona de divisão celular (Gastal \& Nelson, 1994). Em trabalho realizado por Martuscello et al. (2006) com capim-massai, também foram observados aumentos de 64\% nas TAlF com a dose de $120 \mathrm{mg} \cdot \mathrm{dm}^{-3}$ em relação à ausência de adubação nitrogenada. Em outros trabalhos, também foi constatado efeito positivo de N sobre a TAlF (Gastal \& Nelson, 1994; Duru \& Ducrocq, 2000).

Por outro lado, a ausência de efeito da adubação nitrogenada nos períodos das águas e seco pode ter sido, segundo Martha Júnior et al. (2004), decorrente do uso de ureia como fonte de nitrogênio, que pode ter resultado em perdas deste nutriente por volatilização e ou lixiviação do nutriente por chuvas de alta intensidade e, ou irrigação.

Os maiores valores para a TAlF foram observados durante o período das águas na dose de $320 \mathrm{~kg}$ de N.ha ${ }^{-1}$ e densidade de 25 plantas.m ${ }^{-2}$ (8,99 cm.dia $\left.{ }^{-1}\right)$. Durante o período de transição água-seca, os valores da TAlF foram intermediários em comparação aos dos períodos das águas e da seca, com valores de $5,22 \mathrm{~cm}^{-d_{i a}{ }^{-1}}$ para a dose de $320 \mathrm{~kg} . \mathrm{ha}^{-1}$ de $\mathrm{N}$ e densidade de 9 plantas. ${ }^{-2}$. No período seco, foram observados os menores valores da TAlF (3,52 cm.dia ${ }^{-1}$ ) para a dose de $160 \mathrm{~kg} \cdot \mathrm{ha}^{-1}$ de $\mathrm{N}$ e 9 plantas. $\mathrm{m}^{-2}$. Os menores valores relacionados à menor densidade nesta época podem ser atribuídos ao fato de que, em baixas densidades de plantas, a competição no dossel é pouco intensa, o que não estimularia as plantas quanto ao alongamento foliar.

A taxa de aparecimento foliar (TApF) e o filocrono não foram influenciados pela adubação nitrogenada nem pela densidade de plantas. Para a TApF, observaram-se valores de 0,39; 0,11 e 0,07 folhas. dia-1 e, para filocrono, 2,60; 9,15 e 13,07 dias.folha ${ }^{-1}$ para os períodos das águas, de transição água-seca e de seca, respectivamente. Resultados semelhantes ao desse trabalho também foram observados por Pinto et al. (1994), que não constataram efeito das doses de N (100 e $300 \mathrm{mg}$. dm ${ }^{-3}$ em vaso com capacidade de $5 \mathrm{~kg}$ ) sobre as TApF em Panicum maximum cv. Colonião.

No período das águas, o número de folhas vivas (NFV) por perfilho do capim-tanzânia foi influenciado linear e negativamente apenas pela densidade de plantas (Tabela 1). Já no período de transição água-seca e seca, o NFV por perfilho não foi influenciado pela adubação nitrogenada ou pela densidade de plantas e apresentou valores de 5,47 e 4,34 folhas, respectivamente.

O decréscimo no NFV por perfilho com o aumento da densidade de plantas pode ser explicado pela maior competição por luz, que induz as folhas, prioritariamente se alongarem em detrimento ao NFV.

Tabela 1 - Equações de regressão das características morfogênicas e do acúmulo de matéria seca (MS) de capim-tanzânia submetido a doses de nitrogênio (N) e densidades de plantas (D)

\begin{tabular}{|c|c|c|}
\hline Característica & Equação & $\mathrm{R}^{2}$ \\
\hline \multicolumn{3}{|c|}{ Período das águas } \\
\hline Número de folhas vivas & $\hat{Y}=1,78-0,0267270^{*} \mathrm{D}$ & 0,47 \\
\hline Taxa de alongamento de pseudocolmo & $\hat{Y}=0,95+0,00581786^{*} \mathrm{~N}$ & 0,46 \\
\hline \multicolumn{3}{|c|}{ Período transição água-seca } \\
\hline Taxa de alongamento foliar & $\hat{Y}=3,57+0,00325307^{*} \mathrm{~N}-3,0284896^{*} \mathrm{D}$ & 0,68 \\
\hline Taxa de alongamento de pseudocolmo & $\hat{\mathrm{Y}}=1,27-0,0174308^{*} \mathrm{D}$ & 0,51 \\
\hline \multicolumn{3}{|c|}{ Período da seca } \\
\hline Taxa de alongamento foliar & $\hat{Y}=2,41-0,0281250^{*} \mathrm{D}$ & 0,39 \\
\hline Taxa de alongamento de pseudocolmo & $\hat{Y}=0,17-0,00304688^{*} \mathrm{D}$ & 0,43 \\
\hline
\end{tabular}


No período das águas, a taxa de alongamento do pseudocolmo (TAlPC) do capim-tanzânia foi influenciada somente pela adubação nitrogenada (Tabela 1), o que reflete o efeito direto desse nutriente. Além dessa influência, o $\mathrm{N}$ age como fator controlador dos processos de crescimento e desenvolvimento das plantas, proporcionando aumento de biomassa pela fixação de carbono (Nabinger, 2001). Esse resultado confirma que não só a água, mas também a radiação solar incidente, influenciou o desenvolvimento de capimtanzânia durante o período das águas. Portanto, é necessário manejo rigoroso para favorecer o acúmulo de lâminas foliares, e não de pseudocolmos, para garantir oferta de forragem de melhor qualidade para animais em pastejo.

No período de transição água-seca e no período da seca (Tabela 1), a TAlPC de capim-tanzânia foi influenciada linear e negativamente apenas pela densidade de plantas. Essa redução na TAlPC com o aumento da densidade de plantas não era esperada, uma vez que relvados com a maior densidade de plantas tendem, em geral, a apresentar maior alongamento de colmo, em razão da maior competição por luz, uma vez que as plantas tendem a alongar o colmo para facilitar a captação da radiação fotossinteticamente ativa pelas folhas. Além disso, o período de transição água-seca é um período de florescimento intenso das plantas de capim-tanzânia no qual o alongamento de colmos é acelerado. Uma possível explicação para esses resultados pode ser porque em menores densidades, o pseudocolmo se alongou mais paralelamente ao solo como forma de ocupar as áreas descobertas. A colheita foi realizada com 95\% de IL, situação na qual espera-se que o alongamento de pseudocolmo seja reduzido, visto que esse tipo de manejo incide menores acúmulos de pseudocolmo e menor deposição de material senescente.

A ausência de efeito da adubação nitrogenada nos períodos de transição águas-seca e seca não era esperada, todavia, resultados semelhantes foram observados por Fagundes et al. (2006) em capim-braquiária sob lotação contínua. Esses autores não constataram efeito da adubação nitrogenada na taxa de alongamento do colmo.

A relação lâmina:pseudocolmo de capim-tanzânia não foi influenciada $(\mathrm{P}>0,05)$ pela adubação nitrogenada e pela densidade de plantas durante os períodos das águas $(6,85)$, de transição água-seca $(3,01)$ e de seca $(1,57)$. Mesmo sem efeito significativo da adubação nitrogenada, principalmente no período das águas, a relação lâmina:pseudocolmo pode ser considerada alta e confirma a informação de que o capimtanzânia é uma forrageira com altas proporções de folhas em relação aos colmos (Jank, 1995).

Para avaliação da taxa de aparecimento de perfilhos, foram considerados os dados acumulados durante todo o período experimental (janeiro a agosto). A taxa de aparecimento de perfilho (TApP)em plantas de capim-tanzânia foi influenciada linear e negativamente somente pela densidade de plantas $\left(\hat{Y}=37,75-0,266466{ }^{*} \mathrm{D} ; \mathrm{R}^{2}=0,74\right)$.

Segundo Langer (1963), a alta intensidade luminosa favorece o perfilhamento em muitas espécies. Assim, a relação linear negativa da TApP com a densidade de plantas provavelmente decorreu da ausência de competição nas menores densidades, uma vez que a baixa luminosidade na base do dossel de capim-tanzânia pode ter interferido na atividade do perfilhamento. Quando as plantas estão mais espaçadas, onde a competição por nutrientes ainda não é tão alta, a $\mathrm{TA}_{\mathrm{P}} \mathrm{F}$ configura sua importância na produção de perfilhos. Nessa condição, a taxa de perfilhamento pode ser estimada a partir da $\mathrm{TA}_{\mathrm{P}} \mathrm{F}$, caracterizando o site filling (ocupação de sítio), inicialmente proposto por Davies (1974). Em condição de dosséis muito densos, o perfilhamento normalmente é inferior ao potencial da $\mathrm{TA}_{\mathrm{P}} \mathrm{F}$, o que caracteriza o efeito de forte competição entre indivíduos por assimilados e luz e define o conceito de site usage (Skinner \& Nelson, 1995).

Também na avaliação da taxa de mortalidade de perfilhos (TMoP), considerou-se um único período de avaliação (janeiro a agosto). Essa característica ao longo do período experimental foi influenciada $(\mathrm{P}<0,01)$ somente pela densidade de plantas ( $\left.\hat{Y}=25,13-0,241635^{*} D ; R^{2}=0,74\right)$. Essa redução na TMoP com o aumento da densidade de plantas pode ser atribuída à maior frequência de colheita nas parcelas com maior número de plantas.m ${ }^{-2}$ (Figura 10) durante o período (janeiro a agosto). A ocorrência sincronizada de altas TApP e TMoP durante o período experimental caracterizou um padrão intenso de renovação (turnover) da população de perfilhos, comportamento desejado, pois o surgimento de novos perfilhos renova a área foliar e pode melhorar o valor nutritivo da forragem produzida.

O acúmulo de massa seca total (MST) nos períodos das águas, de transição água-seca e de seca apresentou resposta linear positiva à adubação nitrogenada e à densidade de plantas (Figura 3), mas não foi afetado pela interação entre esses fatores.

O maior incremento na produção acumulada de MS (Figura 3) com o maior número de plantas por unidade de área deveu-se ao menor período de crescimento das plantas para atingir 95\% da IL relativamente às menores densidades, o que resultou em maior número de ciclos de crescimento (Figura 10).

A adubação nitrogenada tem efeito direto sobre a área foliar fotossintetizante, como consequência do aumento na taxa de alongamento foliar, que revela a importância do 


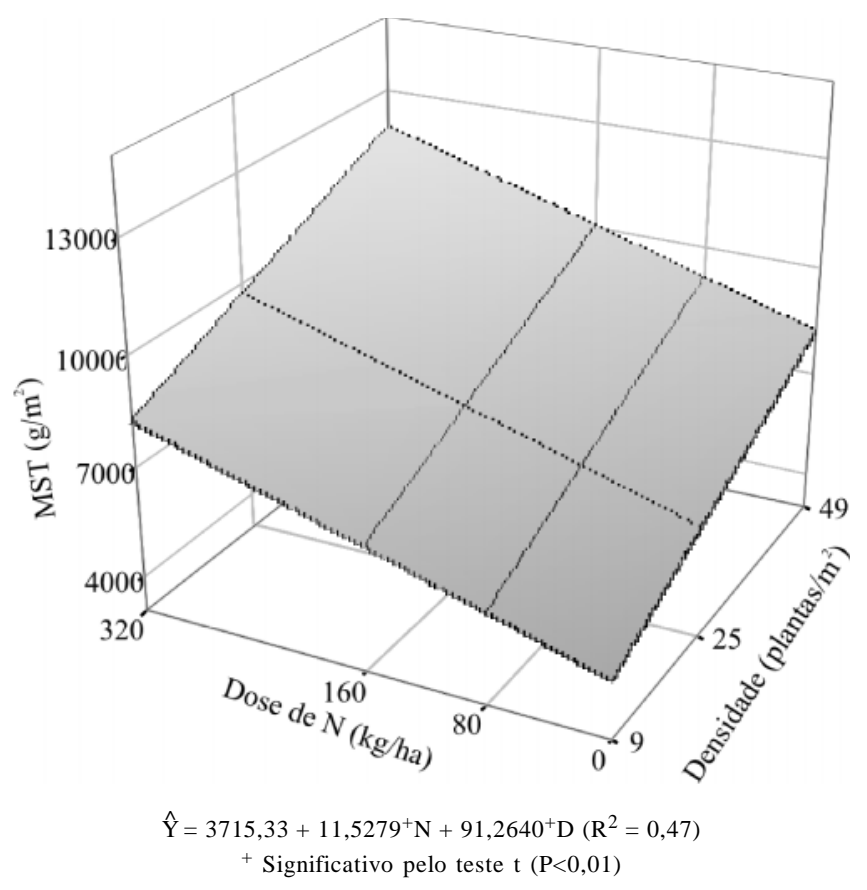

Figura 3 - Acúmulo de massa seca total (MST) do capim-tanzânia adubado com nitrogênio $(\mathrm{N})$ e manejado em diferentes densidades durante os períodos das águas, de transição água-seca e de seca.

nitrogênio para o acréscimo na produção de forragem. Esses resultados corroboram os descritos na literatura (Martuscello et al., 2006; Garcez Neto et al., 2002) sobre o efeito do nitrogênio sobre a produção de MS.

A massa seca foliar (MSF) no período das águas foi influenciada $(\mathrm{P}<0,01)$ somente pela densidade de plantas (Figura 4).

Nos períodos de transição água-seca e de seca, a MSF não foi influenciada $(\mathrm{P}>0,05)$ pela adubação nitrogenada nem pela densidade de plantas e apresentou valores de 741,61 e 455,33 g. $\mathrm{m}^{-2}$, respectivamente.

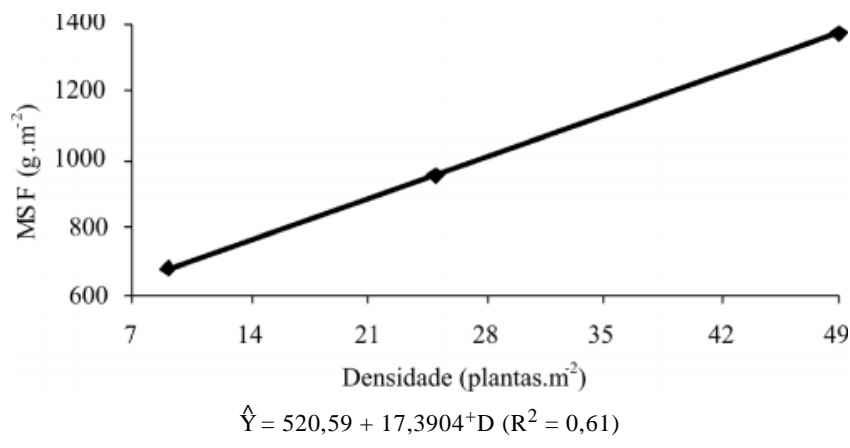

Figura 4 - Produção de matéria seca foliar (MSF) de capimtanzânia em diferentes densidades durante o período das águas.

A produção de MSF foi maior no período das águas, em razão da maior disponibilidade de fatores de crescimento favoráveis, realçando padrão sazonal de produção. Esse padrão de distribuição sazonal de produção de forragem também foi verificado por Tosi (1999) em capim-tanzânia sob pastejo rotativo com aplicação de $\mathrm{N}\left(400 \mathrm{~kg}\right.$.ha.ano $\left.{ }^{-1}\right)$, e por Carnevalli (2003), em capim-mombaça também sob pastejo rotativo.

A produção de massa seca de pseudocolmo (MSPC) de capim-tanzânia foi influenciada $(\mathrm{P}<0,01)$ pela adubação nitrogenada nos períodos das águas $(\hat{\mathrm{Y}}=215,15+$ $\left.0,751085^{+} \mathrm{N}, \mathrm{R}^{2}=0,53\right)$ e de seca $\left(\hat{\mathrm{Y}}=21,33+0,164870^{+} \mathrm{N}\right.$, $\left.\mathrm{R}^{2}=0,34\right)$ (Figura 5). No período de transição água-seca, no entanto, a adubação nitrogenada e a densidade de plantas tiveram efeitos $(\mathrm{P}<0,01)$ na MSPC (Figura 6), mas não foi detectada interação significativa $(\mathrm{P}>0,05)$ entre esses fatores.

O aumento na densidade de plantas e a redução da MSPC são contrários aos descritos na literatura, uma vez que maior densidade de plantas, em geral, resulta em maior alongamento de colmo, em virtude da maior competição por luz, pois as plantas tendem a alongar o colmo para

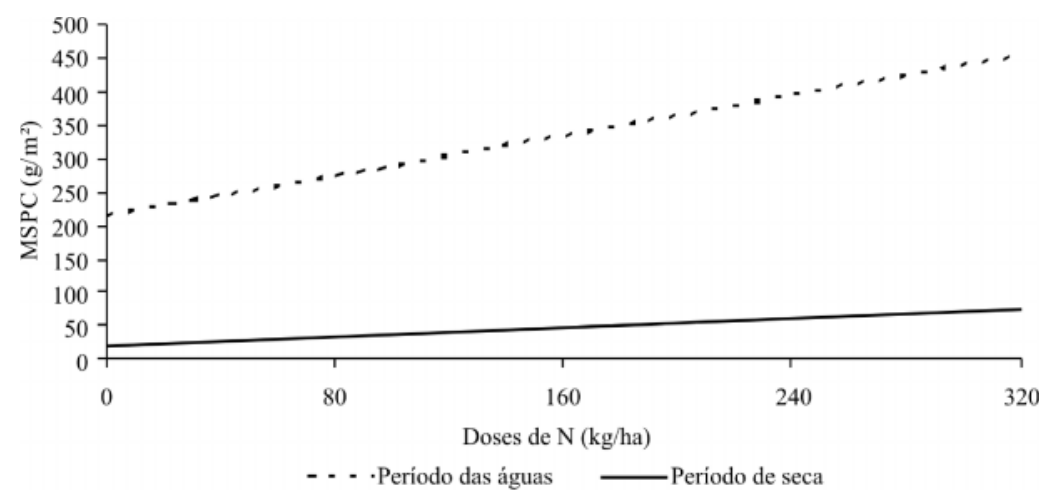

Figura 5 - Produção de matéria seca de pseudocolmo (MSPC) do capim-tanzânia adubado com nitrogênio (N) durante o período das águas e seca. 


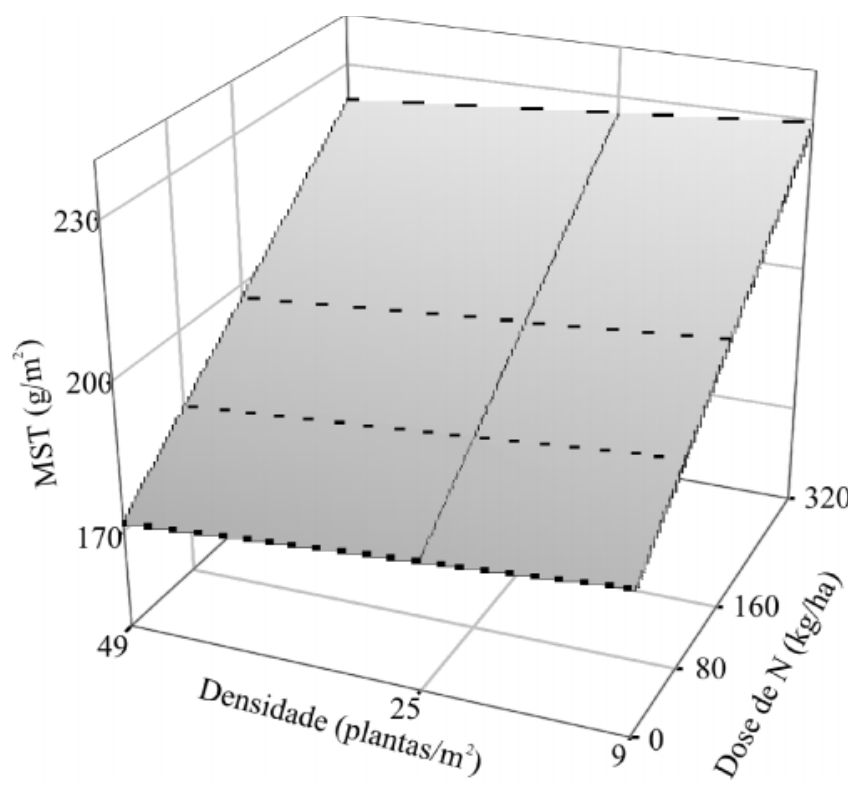

$\hat{\mathrm{Y}}=180,30+0,157597^{+} \mathrm{N}-0,181610^{+} \mathrm{D}\left(\mathrm{R}^{2}=0,58\right)$

Figura 6 - Produção de matéria seca de pseudocolmo (MSPC) do capim-tanzânia adubado com nitrogênio $(\mathrm{N})$ cultivado em diferentes densidades durante o período de transição água-seca.

facilitar a captação da radiação fotossinteticamente ativa pelas folhas.

Em todos os períodos, a maior proporção de lâminas foliares em comparação ao pseudocolmo ocorreu na maior dose de nitrogênio (320 kg.ha-1) e nas densidades de 25 e 49 plantas. $\mathrm{m}^{-2}$ (Figura 7), provavelmente porque a colheita foi realizada quando o dossel de capim-tanzânia interceptava $95 \%$ da radiação fotossinteticamente ativa. Nesse sistema de manejo, a produção de folha é mais acentuada em relação à de colmos.

A proporção de material morto (MM) foi insignificante em todas as doses de nitrogênio e períodos estudados, o que pode ser atribuído ao fato de que a colheita foi realizada quando o dossel de capim-tanzânia atingiu 95\% de IL e houve predomínio de pseudocolmos e lâminas verdes e pouco MM. De fato, essa estratégia, colheita com $95 \%$ de IL, objetiva ofertar aos animais em pastejo forragem com maior proporção de lâminas foliares.

Nos períodos das águas, de transição águas-seca e de seca, a altura do dossel de capim-tanzânia com $95 \%$ de IL foi influenciada $(\mathrm{P}<0,01)$ somente pela densidade de plantas (Figura 8).

$\mathrm{O}$ aumento da altura nas maiores densidades de plantas com $95 \%$ de IL nos períodos das águas, de transição água-seca e de seca pode ser atribuído principalmente ao crescimento mais ereto dos perfilhos em relação ao
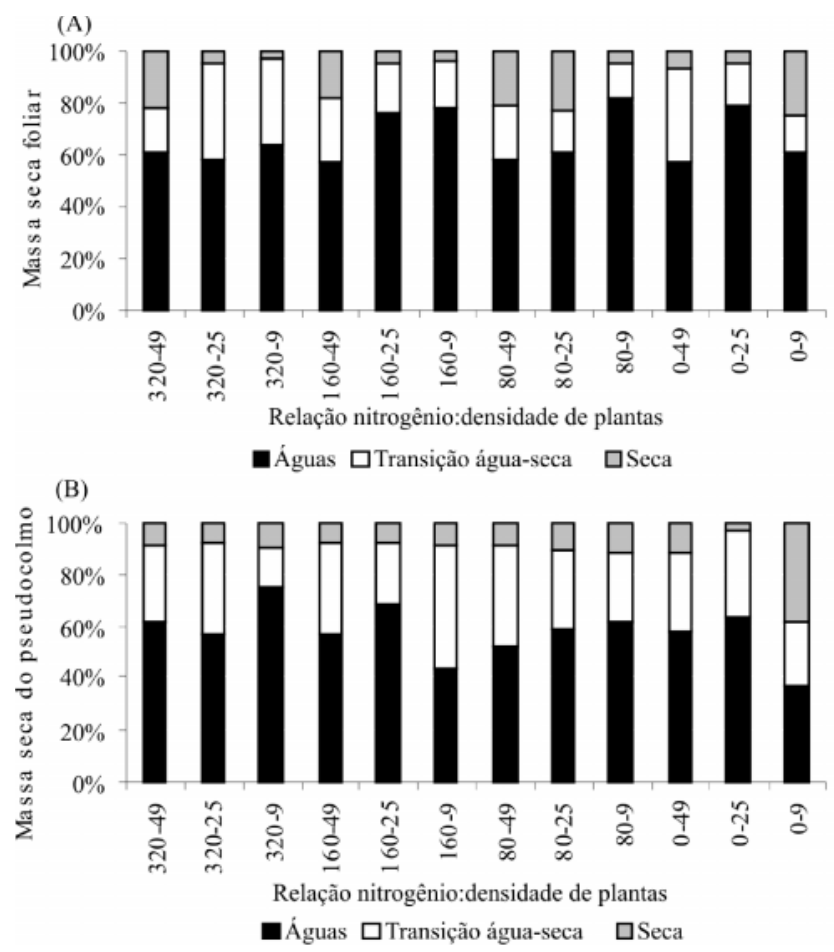

Figura 7 - Porcentagem de massa seca foliar (MSF) e de massa seca do pseudocolmo (MSPC) do capim-tanzânia nos diferentes tratamentos nos períodos das águas (PA), transição águas-seca (PT) e seca (PS).

observado nas menores densidades de plantas, situação em que o desenvolvimento ocorreu quase que paralelamente à superfície do solo.

Independentemente da densidade de plantas, as menores alturas do capim-tanzânia aos $95 \%$ de IL foram observadas no período seco e as maiores, no período das águas, seguido pelo período de transição água-seca. Esse resultado se deve principalmente aos componentes climáticos: luminosidade e temperatura, uma vez que o déficit hídrico foi corrigido pela irrigação. É importante destacar que, somente no período das águas, a altura do dossel de plantas de capim-tanzânia em estabelecimento, em todos os tratamentos, manteve-se próxima aos $70 \mathrm{~cm}$ com $95 \%$ de IL, valor proposto por Da Silva et al. (2004) para capim-tanzânia em pastagens estabelecidas. Em trabalhos conduzidos por Barbosa et al. (2007), Carnevalli et al. (2006) e Mello \& Pedreira (2004), a altura da pastagem foi destacada como uma característica de manejo confiável em pastejo rotativo, no entanto, os resultados obtidos neste estudo indicam que a altura correspondente a $95 \%$ de IL pode variar de acordo com a densidade de plantas em dossel de plantas de capim-tanzânia em estabelecimento.

Portanto, as condições de pré-pastejo com $95 \%$ de IL, com elevada relação com a altura do dossel, que corresponde 


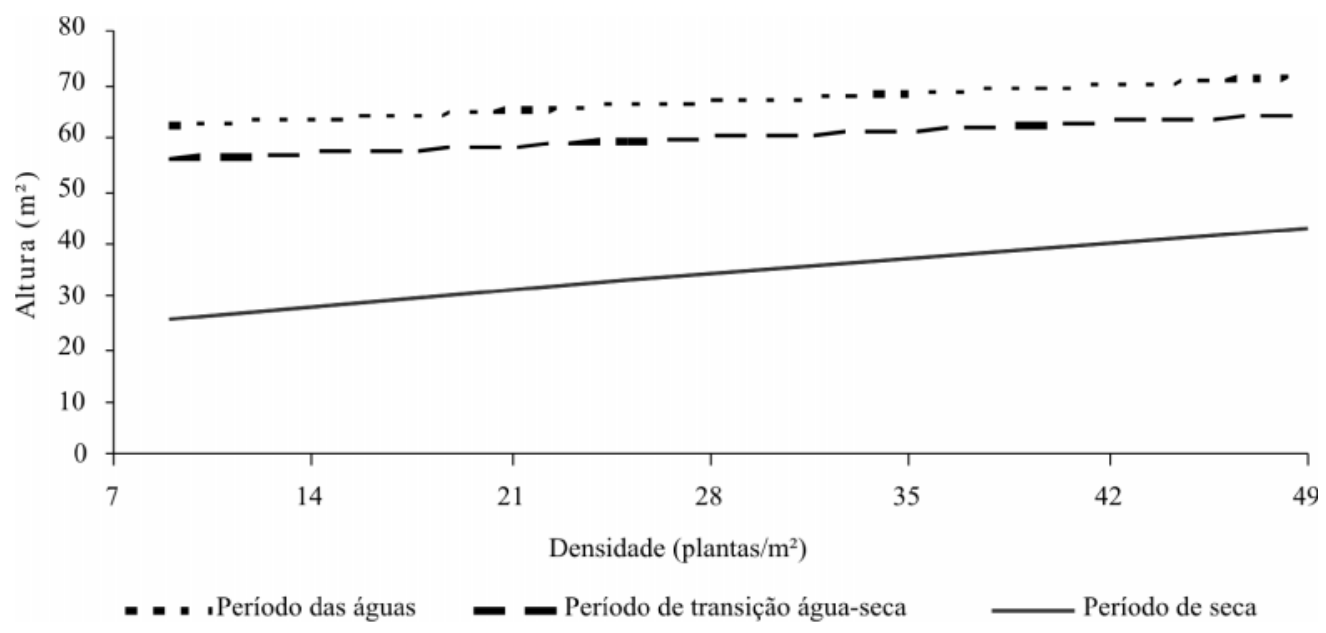

Figura 8 - Altura do capim-tanzânia cultivado em diferentes densidades durante o período das águas, transição água-seca e seca.

a 70 cm para capim-tanzânia, independentemente do período do ano e do estádio fenológico das plantas (vegetativo ou reprodutivo) (Da Silva, 2004), de fato ocorre somente em pastagem estabelecida e com densidade ideal, uma vez que grande parte dos experimentos que levaram a essa afirmativa foi conduzida em pastagens adequadamente estabelecidas e manejadas. Esse comportamento diferenciado indica que pastagens em processo de estabelecimento ou com baixa densidade de plantas não apresentam a mesma dinâmica de desenvolvimento de pastagens estabelecidas, em que a altura com $95 \%$ de IL ocorre de forma homogênea ao longo do ano.

Durante os períodos das águas e de transição águaseca, quando o crescimento é maior, o dossel de capimtanzânia recuperou-se mais rapidamente, resultando em menor intervalo de tempo para atingir 95\% de IL (Figura 9). No período seco, quando o crescimento é menor, em virtude das condições climáticas desfavoráveis, ocorreu o inverso, ou seja, o dossel atingiu 95\% de IL mais tardiamente e, consequentemente, se recuperou mais lentamente. Esse resultado confirma que, além da água, a radiação solar incidente e a temperatura, têm grande influência no desenvolvimento de capim-tanzânia.

As densidades de plantas proporcionaram efeitos marcantes na IL e na frequência de colheita (Figura 10). Na maior densidade (49 plantas. $\mathrm{m}^{-2}$ ), associada às doses de 320 e $160 \mathrm{~kg} \cdot \mathrm{ha}^{-1}$ de $\mathrm{N}$, as plantas com $95 \%$ de IL foram colhidas com frequência de 13 e 12 dias, respectivamente, e possibilitaram maior número de colheitas (nove colheitas). No entanto, apesar de os efeitos da adubação nitrogenada e da densidade de plantas serem detectados somente no período das águas, as maiores doses de nitrogênio e densidades de plantas proporcionaram maior número de colheitas, independentemente da época.
Assim, a implicação prática desses resultados é que a fixação de períodos de descanso para manejo da colheita ou do pastejo nos diferentes períodos do ano pode ser uma estratégia potencialmente perigosa, pois seus efeitos dependem das condições climáticas ou do estádio de desenvolvimento das plantas e podem resultar em perdas significativas de produção e qualidade da forragem e, ou, em superpastejo. Assim, fica a recomendação que, de acordo com o período do ano e com as condições do pasto, haverá mudança no período de descanso.

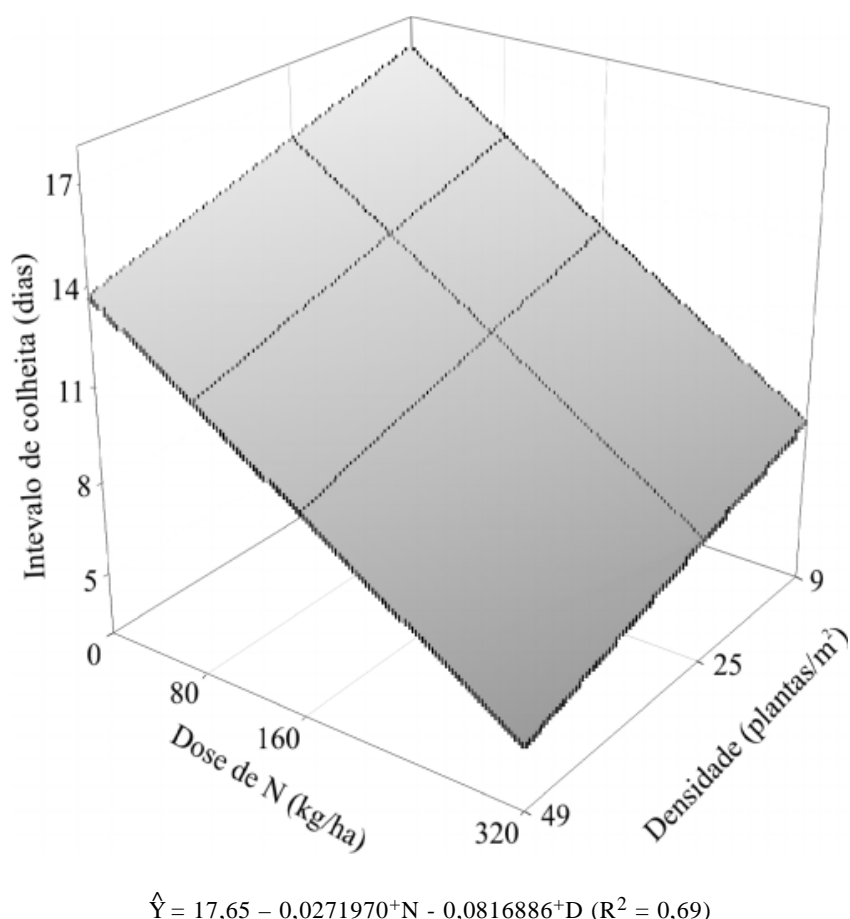

Figura 9 - Intervalo de colheita do capim-tanzânia adubado com nitrogênio $(\mathrm{N})$ e cultivado em diferentes densidades durante o período das águas. 
A adubação nitrogenada e a densidade de plantas tiveram efeito $(\mathrm{P}<0,01)$ sobre o intervalo de colheita do capim-tanzânia no período das águas (Figura 10). Nos períodos de transição água-seca e de seca, o intervalo de colheita de capim-tanzânia foi influenciado $(\mathrm{P}<0,01)$ apenas pela densidade de plantas (Figura 10A).

A resposta negativa do intervalo de colheita à densidade de plantas (Figuras 10) resultou do maior número de plantas e contribuiu para a interceptação mais rápida de $95 \%$ da radiação fotossinteticamente ativa incidente. Portanto, ecossistemas com menor densidade de plantas tendem a interceptar $95 \%$ da radiação mais tardiamente, o que aumenta o intervalo de pastejo ou de colheitas e diminui o número de colheitas (Figura 10A).

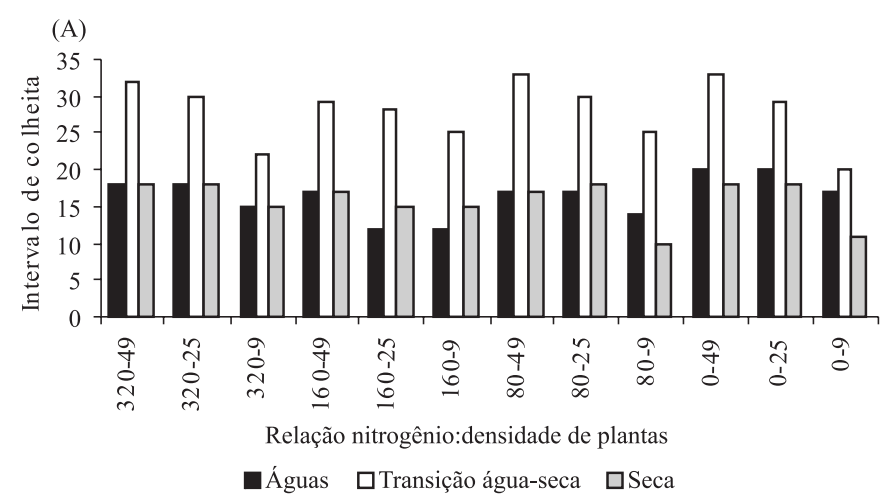

A resposta negativa do intervalo de colheita à adubação nitrogenada no período das águas decorre da estreita relação desse nutriente com o aumento da biomassa, o que influencia significativamente a produtividade do capim-tanzânia e contribui para que mais rapidamente o dossel intercepte 95\% de IL, diminuindo o intervalo e aumentando o número de colheitas (Figura 10B).

No período seco foi observada apenas uma colheita (Figura 10B), o que confirma a influência de outros fatores climáticos, como radiação solar incidente e temperatura, sobre o desenvolvimento do capim-tanzânia, uma vez que a irrigação corrigiu o déficit hídrico. De fato, a luminosidade garante o processo fotossintético e a síntese de açúcares e ácidos orgânicos.

Figura 10 - Intervalo de colheitas (A), em dias, e número de colheitas (B), de capim-tanzânia, a 95\% de interceptação luminosa, nos períodos das águas, de transição água-seca e de seca.

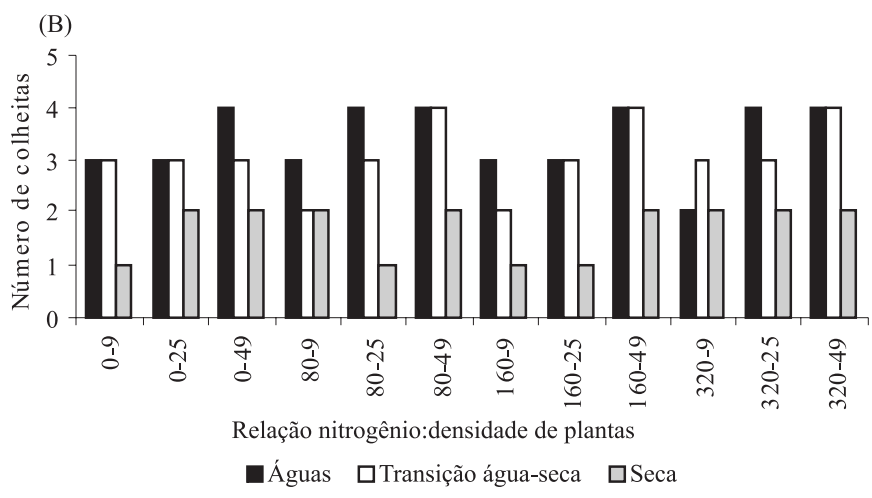

\section{Conclusões}

A densidade de planta de 49 plantas.m ${ }^{-2}$ de capimtanzânia resulta em maior altura do dossel para interceptação de $95 \%$ da luz incidente durante o estabelecimento da forrageira. A altura do capim-tanzânia para interceptar $95 \%$ de luz incidente apresenta variação ao longo do ano. Os maiores valores de altura ocorrem no período das águas, os menores, na seca, e intermediários, no período de transição água-seca, durante o estabelecimento da forrageira. A adubação nitrogenada diminui o intervalo de colheitas do capim-tanzânia.

\section{Referências}

ALEXANDRINO, E.; NASCIMENTO JÚNIOR, D.; MOSQUIM, P.R. et al. Características morfogênicas e estruturais na rebrotação de Brachairia brizantha cv. Marandu submetida a três doses de nitrogênio. Revista Brasileira de Zootecnia, v.33 n.6, p.1372-1379, 2004.

BARBOSA, R.A.; NASCIMENTO JÚNIOR, D.; EUCLIDES, V.P.B. et al. Capim-tanzânia submetido a combinações entre intensidade e freqüência de pastejo. Pesquisa Agropecuária Brasileira, v.42, n.3, p.329-340, 2007.

BÍCEGO, E.G.; ARRUDA, R.G.; LOURENÇO, L.F. et al. Expansão foliar do capim Tanzânia (Panicum maximum Jacq.) submetido a diferentes disponibilidades hídricas. In: CONGRESSO BRASILEIRO DE ENGENHARIA AGRÍCOLA, 32., 2003, Goiânia. Anais... Goiânia: Sociedade Brasileira de Engenharia Agrícola, 2003. (CD-ROM).

CÂNDIDO, M.J.D.; GOMIDE, C.A.M.; ALEXANDRINO, E. et al. Morfofisiologia do dossel de Panicum maximum cv. Mombaça sob lotação intermitente com três períodos de descanso. Revista Brasileira de Zootecnia, v.34, n.2, p.338-347, 2005b.

CARNEVALLI, R.A.; Da SILVA, S.C. ; BUENO, A.A.O. et al Herbage production and grazing losses in Panicum maximum cv. Mombaça under four grazing managements. Tropical Grasslands, v.40, p.165-176, 2006.

Da SILVA, S.S.; PEDREIRA, C.G.S. Princípios de ecologia aplicados ao manejo da pastagem. In: SIMPÓSIO SOBRE ECOSSISTEMAS DE PASTAGENS, 3., 1997, Jaboticabal. Anais... Jaboticabal: Funep, 1997. p.1-12. 
DAVIES, A. Leaf tissue remaining after cutting and regrowth in perennial ryegrass. Journal of Agriculture Science, v.82, p.165-172, 1974.

DURU, M.; DUCROCQ, H. Growth and senescence of the successive grass leaves on a tiller, Ontogenic development and effect of temperature. Annais of Botany, v.85, p.635-643, 2000.

FAGUNDES, J.L.; FONSECA, D.M.; MISTURA, C. at al. Características morfogênicas e estruturais do capim-braquiária em pastagem adubada com nitrogênio avaliadas nas quatro estações do ano. Revista Brasileira de Zootecnia, v.35, n.1, p.21-29. 2006.

GARCEZ NETO, A.F.; NASCIMENTO JÚNIOR, D.; REGAZZI, A.J. et al. Respostas morfogênicas e estruturais de Panicum maximum cv. Mombaça sob diferentes doses de nitrogênio e altura de corte. Revista Brasileira de Zootecnia, v.31 n.5, p.1890-1900, 2002.

GASTAL, F.; NELSON, C.J. Nitrogen use whitin the growing leaf blade of tall fescue. Plant Physiology, v.105, p.191-197, 1994.

GOMIDE, C.A.M.; GOMIDE, J.A. Morfogênese de cultivares de Panicum maximum Jacq. Revista Brasileira de Zootecnia, v.29, n.2, p.341-348, 2000.

HODGSON, J. The significance of sward characteristics in the managment of temperature sown pastures. In: INTERNATIONAL GRASSLAND CONGRESS, 14., 1985, Kyoto. Proceedings... Kyoto: Japonese Society of Grassland Science, 1985. p.63-66.

JANK, L. Melhoramento e seleção de variedades de Panicum maximum. In: SIMPÓSIO SOBRE MANEJO E PASTAGEM, 12., Piracicaba, 1995. Anais... Piracicaba: FEALQ, 1995. p.28-58.

KÖPEN, W. Climatologia. Buenos Aires: Panamericana, 1948. $478 \mathrm{p}$.

LANGER, R.H.M. Tillering in herbage grass. A review. Herbage abstracts, v.33, p.141-148, 1963.
MARTHA JÚNIOR, G.B.; VILELA, L.; BARIONI, L.G. et al. Manejo de adubação nitrogenada em pastagens. In: SIMPÓSIO SOBRE MANEJO DA PASTAGEM, 21., 2004, Piracicaba. Anais... Piracicaba: Fealq, 2004. p.155-215.

MARTUSCELLO, J.A.; FONSECA, D.M.; NASCIMENTO JÚNIOR, D. et al. Características morfogênicas e estruturais de capimmassai submetido a adubação nitrogenada e desfolhação. Revista Brasileira de Zootecnia, v.35, n.3, p.665-671, 2006.

MELLO, A.C.L.; PEDREIRA, C.G.S. Respostas morfológicas do capim Tanzânia (Panicum maximum Jacq. Cv. Tanzânia-1) irrigado à intensidade de desfolha sob lotação rotacionada. Revista Brasileira de Zootecnia, v.33, n.2, p.282-289, 2004.

NABINGER, C. Princípios da exploração intensiva de pastagem. In: SIMPÓSIO SOBRE MANEJO DA PASTAGEM, 13., 1996, Piracicaba. Anais... Piracicaba: ESALQ, 1996. p.59-121.

PINTO, J.C.; GOMIDE, J.A.; MAESTRI, M. Produção de matéria seca e relação folha:caule de gramíneas forrageiras tropicais, cultivadas em vasos, com duas doses de nitrogênio. Revista da Sociedade Brasileira de Zootecnia, v.23, p.433-440, 1994.

SKINNER, R.H.; NELSON, C.J. Elongation of the grass leaf and its relationship to the phyllochron. Crop Science, v.35, n.1, p.4-10, 1995.

VOLENEC, J.J.; NELSON, C.J. Carbohydrate metabolism in leaf meristems of tall fescue. II. Relationship to leaf elongation rates modified by nitrogen fertilization. Plant Physiology, v.74, p.595-600. 1984.

XAVIER, A.C.; COELHO, R.D.; LOURENÇO, L.F. et al. Manejo da irrigação em Pastagem irrigada por pivô-central. Revista Brasileira de Engenharia Agrícola e Ambiental, v.8, n.2/3, p.233-239, 2004. 